\title{
EDUCAÇÃO POPULAR E TECNOLOGIAS DIGITAIS: UMA EXPERIÊNCIA NO ENSINO-APRENDIZAGEM DE FUNÇÕES AFINS E QUADRÁTICAS
}

\section{Popular Education and Digital Technologies: an Experience in Teaching-Learning of Affined and Quadratic Functions}

\author{
Thor Franzen* \\ Rodrigo Sychocki da Silva**
}

\begin{abstract}
Resumo: O presente artigo é um recorte de uma pesquisa feita no âmbito da Educação Popular e está inserida na tendência de Tecnologias da Informação e Comunicação no Ensino da Matemática. O objetivo geral do estudo foi investigar quais potencialidades e desafios emergem no processo de realização de atividades matemáticas sobre funções afins e quadráticas desenvolvidas em um ambiente virtual. A partir de uma perspectiva teórica ancorada em estudos sobre a Educação Popular e Teoria dos Registros Semióticos, a produção de dados para a pesquisa ocorreu em um laboratório de informática com uma turma do pré-vestibular popular Dandara dos Palmares no ano de 2019 e teve característica metodológica qualitativa. Por meio da plataforma online GeoGebraGroups, os materiais utilizados foram construídos e disponibilizados aos participantes, os quais a partir dos dados produzidos e à luz do referencial teórico evidenciamos que o trabalho com o computador oportunizou aos estudantes uma construção e percurso das etapas do raciocínio dedutivo matemático permeado com conversões entre os registros semióticos produzidos ao explorar os objetos matemáticos em estudo.
\end{abstract}

Palavras-chave: Educação Popular. Funções. Tecnologias Digitais. Representação Semiótica.

\begin{abstract}
This article is an excerpt from research carried out within the scope of Popular Education and is part of the trend of Information and Communication Technologies in the Teaching of Mathematics. The general objective of the study was to investigate what potentials and challenges emerge in the process of carrying out mathematical activities on related and quadratic functions developed in a virtual environment. From a theoretical perspective anchored in studies on Popular Education and Theory of Semiotic Records, the production of data for the research took place in a computer lab with a class from the popular pre-university entrance exam Dandara dos Palmares in 2019 and developed under a qualitative methodology. Through the online platform GeoGebraGroups, the materials used were constructed and made available to participants, which, based on the data produced and in the light of the theoretical framework, show that working with the computer provided students with construction and route of the stages of mathematical deductive reasoning permeated with conversions between the semiotic records produced when exploring the mathematical objects under study.
\end{abstract}

Keywords: Popular Education. Functions. Digital Technologies. Semiotic Representation.

\footnotetext{
* Licenciado em Matemática (UFRGS) e atualmente mestrando no curso de Pós-Graduação em Ensino de Matemática (UFRGS). Orcid: https://orcid.org/0000-0001-7111-8397. E-mail: thor.franzen1903@gmail.com.

** Doutor em Informática em Educação (UFRGS). Professor adjunto do Departamento de Matemática Pura e Aplicada (UFRGS). Docente permanente do curso de Pós-Graduação em Ensino de Matemática (UFRGS). Orcid: https://orcid.org/0000-0002-7406-2517. E-mail: sychocki.rodrigo@gmail.com.
} 


\title{
1 Introdução
}

A terceira revolução industrial, que ocorreu no final do século XX e foi liderada pelos avanços na área da informática trouxe mudanças para o século XXI. Segundo Santaella (2003), tem-se agora uma cultura digital cujos tipos de signos em circulação na rede global moldam o pensamento humano e propiciam o surgimento de novos ambientes socioculturais. As mudanças midiáticas oferecem oportunamente uma possibilidade de democratização do conhecimento e da ciência, que pode ter o acesso facilitado por meio da internet. O livre acesso ao conhecimento é uma das premissas da Educação Popular, que constituiu o plano de ação do presente trabalho, uma vez que a parte prática da pesquisa aqui relatada foi realizada com estudantes do pré-vestibular popular Dandara dos Palmares, vinculado ao Instituto Federal do Rio Grande do Sul (IFRS), campus Porto Alegre (RS).

Este texto é resultado de uma pesquisa de conclusão de curso, a qual entendemos estar inserida na tendência das Tecnologias da Informação e da Comunicação (TIC) descreve um estudo realizado com estudantes em um contexto de Educação Popular, a partir de atividades desenvolvidas e disponibilizadas em um ambiente virtual, na plataforma online de grupos do GeoGebra ${ }^{1}$. Inspirados em trabalhos tais como Madruga (2017) e Louzada (2018), a escolha pelo GeoGebraGroups se deu pelo interesse na funcionalidade do espaço virtual e nas potenciais vantagens, inclusive democráticas, que a plataforma dispõe para o trabalho do professor e oferta de múltiplas aprendizagens aos estudantes. Nossa posição converge ao que Louzada (2018) manifesta:

\begin{abstract}
A organização do material em um GeoGebraBook permitiu trabalhar com objetos manipulativos, imagens figurativas e problemas que incentivavam a construção e manipulação de representações mentais. Uma vantagem de produzir o GeoGebraBook e trabalhar com o GeoGebraGroup foi que todas as atividades, com exceção da atividade inicial, foram disponibilizadas e realizadas online. Todas as respostas eram salvas e podiam ser acessadas de qualquer ambiente com internet. (LOUZADA, 2018, p. 74).
\end{abstract}

A escolha pelo tema funções se deu a partir de uma análise inicial das potencialidades oferecidas pelo trabalho com um software interativo. Uma hipótese preliminar e alinhada a um dos referenciais teóricos utilizados na pesquisa diz respeito ao uso da calculadora gráfica, que, ao gerar gráficos a partir de relações matemáticas oportuniza uma conversão entre registros de representação semióticas (DUVAL, 2009) do objeto em estudo. Observou-se a partir de seu uso a possibilidade de uma abordagem intradisciplinar de um conteúdo da matemática, pois permite operar concomitantemente com as representações algébrica (lei da função), geométrica (gráfico da função) e aritmética (valor da função).

O artigo está organizado a partir da próxima seção em fundamentação teórica (seção dois) organizada em três subseções: primeiramente a Educação Popular, a partir dos autores Pini (2012), Pini e Adriano (2011), Brandão (2006), Freire (1981, 2013), Pereira e Pereira (2010), Fiss et al (2012) e Favarão (2011); a segunda subseção aborda sobre as potencialidades no uso das TIC na percepção de Fantin e Girardello (2009), Petris (2016), Massensini (2011), Silva e Pinto (2019), entre outros; a terceira subseção apresenta um viés cognitivo e disserta sobre os registros de representação semiótica propostos por Duval (2009) e abordados também por Silva (2012), Notare et al (2015), Henriques e Almouloud (2016), os quais são a lente utilizada para a análise dos dados produzidos pelos estudantes e apresentados na seção quatro. Na terceira seção é apresentada a caracterização metodológica, materiais e métodos utilizados

\footnotetext{
${ }^{1}$ Disponível em: https://www.geogebra.org/groups. Acesso em março de 2020.
} 
na produção dos dados e na pesquisa. Por fim, na quinta seção manifestamos as considerações finais, destacando aprendizados e perspectivas diante do estudo produzido.

\section{Fundamentação teórica}

\subsection{Educação Popular}

O curso popular em que ocorreu a pesquisa aqui relatada se chama Dandara dos Palmares, e leva o nome da líder quilombola que se revoltou contra a escravidão e o machismo da época colonial. Era esposa de Zumbi e ao lado dele liderava o quilombo dos Palmares, um dos maiores territórios de resistência à escravidão brasileira. Ela cometeu o suicídio no final do século XVII após ser capturada e condenada novamente à escravidão, preferiu a morte. Recentemente ela se tornou uma mártir do movimento das mulheres negras no Brasil, ao lado de outros nomes como Chica da Silva e Marielle Franco. É inspirado nela, na sua luta e nos seus ideais, que surge em 2016, na modalidade institucional de extensão sediado no Instituto Federal de Educação, Ciência e Tecnologia do Rio Grande do Sul (IFRS), o pré-vestibular que acolheu a presente pesquisa.

Atualmente existem outros 18 pré-vestibulares populares em Porto Alegre além do Dandara dos Palmares, que se reúnem em encontros municipais de iniciativa própria ocorridos no Diretório Central dos Estudantes (DCE) da Universidade Federal do Rio Grande do Sul (UFRGS) ou nas suas próprias sedes. Os cursos que oferecem esse serviço de maneira gratuita em Porto Alegre são: Cursinho Popular Carolina de Jesus, Cursinho do PT, Afirmação, Esperança Popular, Kilomba, Resgate Popular, Liberato, ONGEP, PEAC, EducaMed, CEUE, Emancipa (com duas sedes), COLEP (também com duas sedes), S.O.S. Zona Sul e TransENEM e Território Popular - esses dois últimos dividem o prédio do IFRS com o Dandara dos Palmares só que no turno da noite, enquanto que as aulas no Dandara são durante a tarde. Todos os prévestibulares populares são iniciativas da sociedade civil organizada que, de acordo com Pini (2012) é a principal desenvolvedora da Educação Popular.

\footnotetext{
A Educação Popular como práxis social é compreendida como aquela que não está institucionalizada, ocorre dentro e com os grupos populares; é determinada pela realidade e sua perspectiva é histórica. Desenvolve-se na sociedade para se contrapor ao projeto educacional dominante. Por isso é adotada em diferentes contextos, principalmente pelos movimentos sociais do campo e da cidade. Há a defesa, por parte do movimento pela escola pública, gratuita, laica e de qualidade, que a Educação Popular se transforme em uma educação também financiada e oferecida pelo poder do Estado, a serviço dos interesses e projetos com as classes populares. (PINI, 2012, p.1).
}

Conceituada como um movimento civil de educadores identificados com a educação libertadora com uma base simbólico-ideológica de processos políticos de organização e mobilização de setores das classes populares, a Educação Popular é alicerçada na soberania do povo, na justiça social e no respeito integral aos direitos humanos (BRANDÃO, 2006), os quais de acordo com o autor:

Entre graus variáveis de oposição a tal pressuposto, estão aqueles para quem uma das principais características de uma educação popular é justamente a ampliação da sua possibilidade de ser alternativo. Dirigida a sujeitos, grupos e classes populares em suas comunidades de vida e trabalho e, cada vez mais, um assunto, um trabalho, e um 
sistema que o povo participe como presença e, no limite, como poder. Que ela seja portanto: escolar e extra-escolar, pública (municipal, estadual, federal) e alternativamente civil. Bem ou mal, o poder do Estado é responsável pela distribuição do saber escolar e esta foi, não esqueçamos, uma conquista democrática. (BRANDÃO, 2006, p. 29).

A partir do estudo sobre a perspectiva da Educação Popular, um dos conceitos recorrentes entre os autores que escrevem sobre o assunto é o de direitos humanos, os quais são considerados básicos e universais, concedidos a todos independente de gênero, raça, religião, orientação sexual ou política, para garantir a dignidade. Na declaração universal dos direitos humanos, promulgada pela Organização das Nações Unidas (ONU) consta o direito à educação, que é uma temática defendida pela Educação Popular, a qual preconiza que esta deva ser ofertada com qualidade e de maneira universal e gratuita. O seu primeiro artigo já prevê a igualdade entre os seres humanos, visão que permeia toda a declaração e que é fundamental na sociedade democrática. A democracia também é defendida pela Educação Popular, que tem como um dos seus objetivos a participação do povo na política. Segundo Pini e Adriano (2011), uma sociedade é democrática quando há garantia de direitos, distanciando-se da cultura do privilégio e do favor, as práticas democráticas constroem interesses comuns e processualmente diminuem as desigualdades. Ainda segundo os autores:

\begin{abstract}
Nesse sentido, a educação em direitos humanos se apresenta como alternativa de sociabilidade ao mundo contemporâneo, pois seus princípios rompem com a lógica de uma educação geral, na medida que forja espaços de diálogo, crítica, conflito e transformação social. Constrói valores republicanos e se apresenta como plataforma de uma nova cultura política, na medida em que reconhece os espaços de participação política como lócus de socialização do poder. Estimula a cidadania ativa desde a infância, em diferentes espaços educativos, porque compreende que é um direito humano. Alimenta-se da realidade, é intencional, dialética e contraditória. (PINI; ADRIANO, 2011, p. 28).
\end{abstract}

A Educação Popular é, portanto, uma prática educativa cujo ponto de partida é a realidade social. A partir de uma análise do contexto histórico brasileiro, temos que suas origens remontam para a década de 1940, quando se pensava em ofertar educação de base a uma população que era essencialmente rural visando o desenvolvimento econômico e social, bem como a defesa da nação (PEREIRA; PEREIRA, 2010). Nessa e na década seguinte, ocorreram congressos nacionais de educação de adultos, em que educadores debateram sobre suas concepções e práticas educacionais. É nesse cenário que se destaca o pensamento de Paulo Freire, quando em 1962 ele desenvolveu e aplicou uma experiência em alfabetização de adultos realizada na cidade de Angicos, Rio Grande do Norte. Suas ideias são referência para os estudiosos da educação até hoje, mesmo depois da sua morte, pois seu trabalho é considerado inovador e sua produção foi intensa.

Nos anos 1970, durante o regime militar, o trabalho que Paulo Freire propôs, se opôs à educação bancária, sendo preconizada uma educação para a liberdade, em que homens e mulheres se descobrem como produtores culturais e compreendem a relação do homem com a natureza e com a sociedade, abraçando seu potencial transformador. O contraponto é a educação bancária, que seria o ensino pela coerência mercadológica, em que o processo educativo é uma mercadoria e um ato permanente de depósito de conteúdo. Não há espaço nesse modelo educacional para a superação da relação do educador com o educando, que, pelo contrário, é enfatizada (FREIRE, 1981). Com isso, a posição de Pereira e Pereira (2010) dialoga com a posição frente a uma educação libertadora, os quais refletem: 
Essa experiência de alfabetização, a partir dos princípios da educação para a liberdade, procurava superar a educação domesticadora, ou educação bancária como assim denominou. Para Freire, a educação popular seria um espaço em que o homem ultrapassaria sua situação de homem-objeto a homem sujeito-histórico transformador. O que se pretendia era a construção de um projeto político que possibilitasse superar a dominação do capital sobre o trabalho e, assim, reformular a forma de organização da sociedade. (PEREIRA; PEREIRA, 2010, p. 77).

Paulo Freire continuou sua produção científica e seu impacto social, inclusive como secretário de educação do estado de São Paulo, durante a redemocratização e a década de 1990 até o seu falecimento em 1997. Freire propunha a conscientização ao invés da memorização e da mecanização do trabalho e do estudo, onde "ensinar não é transferir conhecimento, mas criar as possibilidades para a sua produção ou a sua construção" (FREIRE, 2013, p. 24), discurso que dialoga com a seguinte posição frente aos diversos contextos educacionais, conforme refletem Pereira e Pereira (2010):

\begin{abstract}
O potencial desse projeto político de educação está na forma como, mesmo diante de muitas dificuldades e precariedades, a educação popular sobreviveu às ações de desmobilização e desmonte dos movimentos populares. Ela não só resistiu e permaneceu atuante, como contribuiu para que educadores e educadoras levassem para as escolas o que aprenderam em sua militância política nos movimentos sociais e sindicais. Os governos democráticos e populares, que foram ganhando espaço na sociedade brasileira a partir dos anos 80, também se apoiaram nas experiências da educação popular para a definição de políticas educacionais. (PEREIRA; PEREIRA, 2010, p. 83).
\end{abstract}

Mesmo após a sua morte, as ideias de Paulo Freire seguem atuais. O Dandara dos Palmares é um dos projetos que existe fundamentado nas ideias de educação libertadora, transformadora e acolhedora. Entendemos que a partir dessas ideias e reflexões que o ingresso no ensino superior representa para os estudantes uma esperança de mudança de realidade, tendo em vista que por vezes os frequentadores desse espaço educacional serão os primeiros das suas famílias a estudar em uma faculdade. Todavia, a exposição de conteúdos e resolução de questões de vestibular não são os únicos objetivos do pré-vestibular Dandara dos Palmares, que tem a responsabilidade também de libertar os alunos de preconceitos (tantos seus quanto de terceiros) rompendo assim o ciclo da opressão.

Frente a isso, é papel do professor manter as portas abertas em todos os casos, oferecendo uma mão amiga aos estudantes que por algum motivo esteja com dificuldades de frequentar as aulas presenciais. Segundo Fiss et al (2012) o estudante precisa se sentir "motivado a comparecer às aulas, o professor precisa estimular o pensamento críticoquestionador. A arte e todas as demonstrações de cultura popular podem e devem estar presentes no currículo escola" (FISS et al, 2012, p. 155). Com isso, é responsabilidade do professor valorizar a história do sujeito com uma postura acolhedora, e isso é um dos pilares da Educação Popular, segundo Favarão (2011):

\footnotetext{
Quebrar os paradigmas seculares de exclusão na escola é imperativo para uma educação em direitos humanos. Construir uma cultura da paz, de reconhecimento das diferenças sociais, econômicas, religiosas, culturais e de orientação sexual ou ideológica demanda gerenciar uma escola aberta, universal e pluridimensional, onde caibam todos, respeitados os acordos também estabelecidos por todos. (FAVARÃO, 2011, p. 192).
}

Consideramos que em um espaço de pré-vestibular popular não seja suficiente abordar os conteúdos solicitados nas avaliações do Exame Nacional do Ensino Médio (ENEM) e 
vestibulares, torna-se necessário também educar para o mundo, para a vida e para a cidadania, garantindo acesso à educação de qualidade mesmo depois da idade escolar para aqueles que não têm condições de pagar por ela. Esse público-alvo é composto por sujeitos da Educação Popular e é importante que os professores tenham uma abordagem plural, não discriminatória e valorizadora das suas histórias egressas, buscando divulgação e valorização dos direitos humanos. Novamente, ancorado nas ideias de Pini (2012):

\begin{abstract}
Compreender que a educação popular requer uma articulação com a educação em direitos humanos, a qual compreendemos como a educação permanente, crítica, dialógica, participativa e fundamentada em uma teoria que assegure a compreensão da realidade e voltada para a mudança da estrutura da sociedade capitalista; uma educação em que as diretrizes têm clareza dos seus valores e princípios e não se foca na transmissão de conhecimentos; é a educação que envolve os cidadãos para o processo de construção do exercício da cidadania ativa, ocupação do espaço público e permanente luta pelos direitos sociais. (PINI, 2012, p.8).
\end{abstract}

Um aspecto inerente da Educação Popular no século XXI é o uso das TIC no contexto educacional. Torna-se necessário refletir sobre essa temática quando o assunto é a inclusão digital, tendo em vista o impacto provocado pelo seu uso na configuração da sociedade atual. No presente momento, os celulares já são populares a ponto de que quase todos têm acesso a um aparelho, porém a exclusão digital não é exatamente um distanciamento da tecnologia, mas sim a incapacidade de criar maneiras mais justas da distribuição de riqueza simbólica e material (SCHWARTZ, 2000). Portanto, se faz necessário refletir sobre a inclusão digital de uma forma dialética, "deixando de lado qualquer iluminismo ingênuo ou perspectivas assistencialistas de distribuição de equipamentos” (FANTIN; GIARDELLO, 2009, p. 72).

\title{
2.2 TIC na Educação
}

A inserção das tecnologias no cotidiano exige uma capacitação cada vez maior das pessoas para seu uso (MADRUGA, 2017). Todavia, segundo Fantin e Giardello (2009), a educação abre mão da socialização dos conhecimentos aliados aos valores humanos quando enfatiza o tecnicismo instrucional. Temos então o argumento da cidadania, o qual preconiza: "programas sociais de inclusão digital são praticados como possibilidade de acesso a tecnologias da informação e comunicação, as quais são importantes para que se promovam os direitos políticos, civis e sociais" (MASSENSINI, 2011, p. 1). Consideramos que a inclusão digital tem importância no exercício da cidadania plena, pois garante o acesso à informação bem como o direito à livre manifestação e participação política, conforme Massensini (2011) destaca:

\footnotetext{
A inclusão digital pode promover a participação do indivíduo no ciberespaço, que se torna a cada dia a esfera dos debates públicos e que se apresenta como espaço de decisões do Estado. E, ainda, a considerar que antes mesmo da conscientização crítica do ciberespaço, o que levará o indivíduo a buscar informações sociais nesse espaço será a necessidade de pertencimento a algum lugar, espaço de trabalho, profissão ocupação. (MASSENSINI, 2011, p. 6)
}

A presença de computadores nos lares e de smartphones nos bolsos causou mudanças nas relações sociais e na forma de pensar, graças à conexão global em rede proposta, a qual resultou na transição para uma cultura digital. Para Santaella (2003), a formação da cultura digital se deve aos novos processos de comunicação que aconteceram nesses meios e acabaram 
por moldar o pensamento e a sensibilidade dos sujeitos, bem como suas práticas sociais, crenças e valores. Segundo a autora:

Para compreender essas passagens de uma cultura para outra, que considero sutis, tenho utilizado uma divisão das eras culturais em seis tipos de formações: a cultura oral, a cultura escrita, a cultura impressa, a cultura de massas, a cultura das mídias e a cultura digital. Antes de tudo, deve ser declarado que essas divisões estão pautadas na convicção de que os meios de comunicação, desde o aparelho fonador até as redes digitais atuais, não passam de meros canais para a transmissão de informação. Por isso mesmo, não devemos cair no equívoco de julgar que as transformações culturais são devidas apenas ao advento de novas tecnologias e novos meios de comunicação e cultura. São, isto sim, os tipos de signos que circulam nesses meios, os tipos de mensagens e processos de comunicação que neles se engendram os verdadeiros responsáveis não só por moldar o pensamento, mas também por propiciar o surgimento de novos ambientes socioculturais. (SANTAELLA, 2003, p. 24).

Com a hegemonia da cultura digital, especificamente entre o público da escola, a tecnologia da educação está se alterando. O livro didático e o quadro negro estão sendo gradativamente substituídos ou complementados por instrumentos eletrônicos que desempenham as mesmas funções, tais como o e-book e a lousa digital, respectivamente. Esse processo precisa ser acelerado com investimentos em educação, de acordo com Petris (2016):

A cultura digital está presente no cotidiano da maioria das pessoas. Sendo assim, temos que aceitá-la e inseri-la no contexto escolar, pois os alunos não querem e não podem mais estar num contexto escolar como era há alguns anos. Ensinar com o quadro, livro e caderno não é mais suficiente. E assim, precisamos inserir as novas tecnologias, caso contrário, a escola ficará defasada e 'antiquada' diante da cultura digital. (PETRIS, 2016, p. 9).

Segundo a autora, as tecnologias digitais estão transformando as interações, que se tornaram instantâneas. Essas mudanças cobram que a formação de professores seja direcionada nesse sentido, buscando a inserção delas na prática pedagógica, pois muitos estudantes em idade escolar e acadêmica hoje já nasceram na cultura digital, chamados de nativos digitais, enquanto os professores são considerados imigrantes digitais (PETRIS, 2016). O uso das mídias digitais no cotidiano escolar, como ferramenta didática e a inserção dos softwares educativos em sala de aula é mais que uma inovação, é uma necessidade no mundo da informação do século XXI (FANTIN; RIVOLTELLA, 2003), onde adolescentes e crianças se comunicam quase exclusivamente por artefatos digitais, conforme refletem Silva e Pinto (2019) sobre esse novo olhar sobre a aprendizagem:

É valorizada a utilização da tecnologia nas aulas de matemática, visto que a mesma
deve acompanhar criticamente o desenvolvimento tecnológico contemporâneo,
tomando contato com os avanços das novas tecnologias nas diferentes áreas do
conhecimento para se posicionar frente às questões de nossa atualidade. Ainda é
mencionado que ao inserir e fazer uso das tecnologias permite-se afirmar que aprender
matemática no Ensino Médio deve ser mais do que memorizar resultados dessa
matéria e que o conhecer matemático deve estar ligado ao saber fazer matemática e
de um "saber pensar matemático". (SILVA; PINTO, 2019, p. 111).

A educação digital ganha importância, pois oportuniza o diálogo com os estudantes sobre o uso da internet de forma cidadã, o que pode eventualmente ter efeitos catastróficos se mal feito. Segundo Fantin e Girardello (2009) “a mídia-educação é ao mesmo tempo um campo de reflexão teórica sobre as práticas culturais e o fazer educativo, e assim, pode constituir-se 
como um espaço de aproximação significativa entre cultura, educação e cidadania" (FANTIN; GIRARDELLO, 2009, p. 79).

Uma potencialidade trazida por Madruga (2017) é que a autora reconhece que o uso de um software educativo em sala de aula pode causar uma interação futura por parte do estudante moderno, já que ele está constantemente conectado a internet pela tela do celular. Segundo a autora, "com os tutoriais, o estudante pode aprender sozinho seu funcionamento e a partir daí, manipular o software, fazer construções e aprender conteúdos utilizando a manipulação" (MADRUGA, 2017, p.3). O conhecimento técnico relativo à operação do aplicativo é importante para o desenvolvimento cognitivo do estudante e traz potencialidades para o estudo de matemática e de seus conteúdos específicos. As próprias Orientações Curriculares para o Ensino Médio (BRASIL, 2006, p.87) apresentam "a matemática como ferramenta para compreender a tecnologia e a tecnologia como ferramenta para compreender a matemática". Todavia a educação não deve se limitar ao ensino de técnicas relativas ao aplicativo, mas também propor uma discussão sobre o uso das mídias digitais e seu papel na sociedade.

O GeoGebra tem uma aplicação que pode ser instalada em computadores com sistema operacional compatível. A plataforma foi escolhida para o trabalho da pesquisa não só por não requerer uma instalação prévia do programa, mas também por oferecer o GeoGebraGroups como funcionalidade, oportunizando que esse fosse um Ambiente Virtual de Aprendizagem (AVA). Os AVAs são softwares educacionais via internet, destinados ao apoio das atividades de Educação a Distância (EAD), sejam essas semipresenciais ou presenciais. Eles oferecem um conjunto de tecnologias as quais permitem desenvolver as atividades no tempo, espaço e ritmo de cada participante (RIBEIRO et al, 2007). Ainda segundo os autores:

\footnotetext{
Os AVAs geralmente são desenvolvidos por instituições acadêmicas ou empresas privadas. Eles fornecem aos participantes ferramentas a serem utilizadas durante um curso, para facilitar o compartilhamento de materiais de estudo, manter discussões, coletar e revisar tarefas, registrar notas, promover a interação entre outras funcionalidades. Eles contribuem para o melhor aproveitamento da educação e aprendizagem na EAD, pois oferece diversos recursos para a realização das aulas e interações entre professores e alunos. (RIBEIRO et al, 2007, p. 4).
}

Mesmo fora do contexto da EAD, o uso de um AVA, especificamente do GeoGebraGroups, como ferramenta de ensino foi considerado com potencial por permitir um acesso dos estudantes à sequência de atividades nos momentos tanto de sala de aula presencial quanto de forma remota, ou seja, apresentou vantagens ao trabalho do professor e de certa forma entendemos que incentivou o estudo por parte do estudante. Os AVAs são centrados em conteúdos e atividades pré-determinadas, cujo processo já está previsto de antemão. Eles devem oportunizar ajuda tutorial rapidamente acessível, meios de informação integrados, conteúdos enfocados a partir de diferentes pontos de vista, possibilidade de interagir com diferentes conteúdos, contato com o professor e o planejamento detalhado da estrutura de aprendizagem (DOTTA, 2011).

O uso do GeoGebra sob a modalidade de AVA trouxe, no âmbito da pesquisa realizada pontos relevantes para a aprendizagem de Matemática quando analisado sob a perspectiva intradisciplinar. No presente texto destacamos ser necessário não confundir com interdisciplinaridade, fenômeno que estabelece relações entre as disciplinas escolares, ou com a transdisciplinaridade, que se propõe a ir além das disciplinas e promover um aprendizado que desperte uma consciência sobre o conhecimento (FARIA; MALTEMPI, 2019). 


\subsection{Intradisciplinaridade e Registros de Representação Semiótica}

A intradisciplinaridade nos faz refletir nas relações de ramificações de uma mesma disciplina. No caso da Matemática as ramificações da disciplina em geometria, álgebra e aritmética dão origem a três diferentes formas de representação. A representação aritmética é essencial para a compreensão de um caso particular, mas isolada não é suficiente para a solução de casos gerais. A representação geométrica é intuitiva, porém apresenta imprecisões quando desenhada à mão livre por professores ou estudantes devido escalas e a inexatidão de medições. Tais falhas podem ser amenizadas pelo software que constrói o gráfico em proporção adequada. Enquanto a representação algébrica é concisa, geral e efetiva na formalização e análise de padrões, dispõe de vários símbolos algébricos que podem dificultar a interpretação de resultados. Todas as representações devem ser exploradas de forma simultânea, pois a conexão entre ramificações da Matemática é capaz de oportunizar uma compreensão dos significados dos conceitos, valorizar as semelhanças e eliminar a fragmentação das ideias, contribuindo assim para a ampliação da compreensão que permeia o entendimento dos assuntos matemáticos conforme manifestam Faria e Maltempi (2019). Segundo os autores:

Por meio das três representações concomitantes, o GeoGebra permite que as desvantagens de cada forma de representação sejam compensadas com as vantagens das outras. É nesse sentido que a abordagem que busca desenvolver e explorar o raciocínio proporcional em uma perspectiva intradisciplinar é favorecida por esse software. Ademais, o uso do GeoGebra permite experimentar, criar estratégias, fazer conjecturas, explorar, argumentar e deduzir propriedades matemáticas. (FARIA; MALTEMPI, 2019, p. 355).

Apontado nas orientações curriculares para o Ensino Médio, são características dos softwares oferecerem diferentes representações para um mesmo objeto matemático (numérica, algébrica e geométrica), bem como possibilitar a expansão da base de conhecimento dos estudantes por meio de macro construções, as quais seriam funções de construção geométrica oferecidas pelo software (BRASIL, 2006). Entendemos que as representações mencionadas anteriormente tenham relação com as representações semióticas teorizada por Duval (apud MORETTI, 2012), as que formam o sistema de Registros de Representação Semiótica de um objeto matemático. Conforme explica o autor:

\footnotetext{
As representações mentais recobrem o conjunto de imagens e, mais globalmente, as conceitualizações que um indivíduo pode ter sobre um objeto, sobre uma situação e sobre o que lhe é associado. As representações semióticas são produções constituídas pelo emprego de signos pertencentes a um sistema de representações que tem inconvenientes próprios de significação e de funcionamento. Uma figura geométrica, um enunciado em língua natural, uma fórmula algébrica, um gráfico são representações semióticas diferentes. Consideram-se, geralmente, as representações semióticas como um simples meio de exteriorização de representações mentais para fins de comunicação, quer dizer para torná-las visíveis ou acessíveis a outrem. Ora, este ponto de vista é enganoso. As representações não são somente necessárias para fins de comunicação, elas são igualmente essenciais à atividade cognitiva do pensamento. (DUVAL, 1993, apud MORETTI, 2012, p. 269).
}

A união das representações (algébrica, gráfica, simbólica e em língua materna) forma o sistema de registros de representação semiótica, por onde o estudante transita por meio de conversões mentais entre os registros. Ainda segundo o autor:

A especificidade das representações semióticas consiste em serem relativas a um sistema particular de signos, a linguagem, a escritura algébrica ou os gráficos cartesianos, e, em poderem ser convertidas em representações 'equivalentes' em um 
outro sistema semiótico, mas podendo tomar significações diferentes para o sujeito que as utiliza. A noção de representação semiótica pressupõe, então, a consideração de sistemas semióticos diferentes e de uma operação cognitiva de conversão das representações de um sistema semiótico para outro. (DUVAL, 2009, p. 32).

Segundo Silva (2012), a importância das representações semióticas não reside apenas nas suas compreensões individuais, mas também na conversão e tradução de uma representação para outra.

\begin{abstract}
Pode-se afirmar que ao representar, tratar e converter em representações semióticas é necessário a mobilização de sistemas cognitivos específicos para cada uma das atividades propostas aos alunos. Com isso, somente pode-se aprender efetivamente as ideias matemáticas através das representações semióticas dos objetos matemáticos. Durante o processo de aprendizagem é importante que o aluno saiba manipular as representações semióticas, com a finalidade de transformá-las em outras, se necessário. (SILVA, 2012, p.47).
\end{abstract}

De acordo com Notare et al (2015), cada objeto é expresso por diferentes registros. Temos o registro gráfico, no sistema cartesiano de coordenadas; o registro aritmético, expressado por meio dos números envolvidos no problema; o registro algébrico, que se manifesta no campo simbólico dos signos utilizados para escrever a matemática; e o registro em língua materna, dado pela compreensão e expressão do aluno do objeto estudado. O trabalho com as representações individuais e a conversão de registros aborda a intradisciplinaridade matemática ao mostrar diferentes interpretações (aritmética, algébrica e geométrica) de um mesmo conteúdo em estudo, no caso da nossa pesquisa as funções. De acordo com os autores:

\begin{abstract}
Os sistemas de representação semiótica têm importante papel no processo de aprendizagem da matemática. Os objetos matemáticos, em geral, são expressos por meio de diferentes registros, tais como o registro algébrico com suas regras de funcionamento, o registro gráfico, com regras de tratamento que levam à identificação dos elementos pertinentes de uma figura e, dentro deste registro, inclui-se o de natureza gráfica, dado por sistema de coordenadas cartesianas e curvas que nele são traçadas, o registro discursivo em linguagem natural, e também com outros símbolos, com suas regras convencionais de comunicação. (NOTARE et al, 2015, p. 4).
\end{abstract}

Também fundamentado nas ideias de Duval há o trabalho de Henriques e Almouloud (2016) que explica a teoria recorrendo a definições e conceitos chave para a sua compreensão. Além de representação semiótica, temos o signo o qual é "um sinal mobilizado por alguém (sujeito) capaz de permitir-lhe identificar um sistema ou registro de representação semiótico" (HENRIQUES; ALMOULOUD, 2016, p. 468). Os autores citam ações com as diferentes representações, como a formação, caracterizada pela aplicação de regras de conformidade e seleção de características do conteúdo envolvido; e o tratamento, transformação interna de um registro dentro dele mesmo. Os autores também definem a conversão de registros como uma transformação entre representações diferentes, e a coordenação de registros, a qual é o reconhecimento de diferentes representações concomitantes de um objeto.

Pelo fato da importância para a atividade cognitiva dos estudantes a análise de dados produzidos na pesquisa aconteceu sob a luz desse referencial teórico, buscando nas respostas fornecidas para as atividades evidências que permitissem inferir se ocorreu a construção e conversão entre as formas de registro inerentes aos assuntos em estudo. A próxima seção apresenta os procedimentos metodológicos, materiais e métodos utilizados na produção dos dados. 


\section{Metodologia, materiais e métodos utilizados}

O estudo foi feito de acordo com a estrutura de investigação proposta por Fiorentini e Lorenzato (2007), na qual o problema e as hipóteses geram uma pergunta de pesquisa, a ser respondida por dois caminhos, pesquisa bibliográfica e investigação empírica. A composição dos dois métodos traz resultados que são filtrados, avaliados e transformados em uma conclusão, com impactos na área do conhecimento, bem como na prática profissional geral e específica do pesquisador.

O presente trabalho de pesquisa surgiu a partir de observações constatadas por meio da experiência e pesquisa bibliográfica, de que a mecanização da matemática escolar, dada pela repetição de métodos e um afastamento do ensino diante do potencial que as mídias digitais têm quando utilizadas, caminha na direção oposta à aprendizagem. Diante desse contexto, a pergunta diretriz de investigação foi: De que maneira o material didático disponível em um ambiente de aprendizagem virtual impacta o ensino e a aprendizagem de funções na perspectiva da intradisciplinariedade matemática?

Os dados foram produzidos a partir das respostas dos estudantes às questões de duas atividades formuladas, uma sobre funções afins e outra sobre funções quadráticas, e também a partir das respostas fornecidas a dois questionários, um ocorrido antes das atividades e outro ao final. Durante a produção dos dados foram observados os princípios metodológicos propostos por Rezat (2008), o qual estabelece três critérios para a coleta de dados. O primeiro critério é o registro da utilização do material pelos estudantes em sala de aula, o qual foi feito por meio do diário de observação e do envio de respostas via plataforma. O segundo critério diz respeito a minimizar a interferência externa e do pesquisador no ambiente a ser estudado, sendo esse um critério difícil de garantir na prática, uma vez que o pesquisador está envolvido na função de professor durante a realização das atividades. $\mathrm{O}$ terceiro e último critério proposto pelo autor diz respeito à coleta de dados quando os estudantes não estão em sala de aula, pois o uso de diversos materiais de ensino, inclusive digitais, também se dá de maneira autônoma (REZAT, 2008).

O material digital foi criado e disponibilizado no GeoGebraGroups e tem como objetivo explorar as representações semióticas sobre o conteúdo de funções (escrita, geométrica, aritmética e algébrica), bem como a conversão entre eles. A turma participante da pesquisa era composta por 28 estudantes, sendo que 25 autorizaram o uso das informações para a pesquisa. Após a instituição, cenário da prática de ensino, aceitar e concordar com os termos da pesquisa, as aulas, que totalizaram dois encontros presenciais, ocorreram na turma do curso pré-vestibular popular Dandara dos Palmares, com sede no IFRS, Campus Porto Alegre. As atividades encontram-se atualmente disponíveis na internet, e podem ser acessadas por meio dos códigos Quick Response (QR) mostrados na Figura 1 ou por meio de links ${ }^{23}$.

Figura 1 - Códigos QR para acesso às atividades.

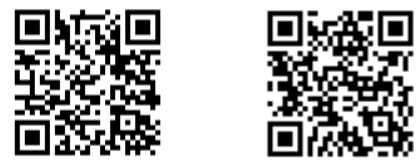

Fonte: Os autores.

\footnotetext{
${ }^{2}$ Atividade sobre função afim: https://www.geogebra.org/m/beafvqty. Acesso em março de 2020.

${ }^{3}$ Atividade sobre função quadrática: https://www.geogebra.org/m/dkkjkpv4. Acesso em março de 2020.
} 
A próxima seção apresenta uma análise das respostas dos estudantes para as atividades realizadas, as quais constituíram o conjunto de dados utilizados para elaborar uma resposta para a questão de pesquisa. Nossas análises, de cunho qualitativo, foram centradas na observação sobre as ações dos estudantes diante das explorações das atividades virtuais, verificando se havia trânsito entre as formas de registros e representação, qualidade da atividade argumentativa e por fim, as potencialidades e desafios inerentes ao fazer pedagógico docente permeado pelo uso da tecnologia digital em um espaço de Educação Popular.

\section{Apresentação e análise dos dados}

O quantitativo de estudantes que participou da atividade foi de 28 sendo que três desses não assinaram o termo de consentimento para participação da pesquisa e, portanto, não tiveram suas respostas analisadas. Os 25 estudantes que produziram informações, as quais foram utilizadas nas análises serão nomeados pelas letras do alfabeto, de A até Y. As análises que aparecem a seguir não são sobre as respostas manifestadas de maneira geral, mas sim de maneira pontual por meio das situações que, no decorrer da pesquisa, mostraram-se pertinentes frente ao referencial teórico apresentado.

Uma análise sobre a primeira questão (Figura 2) da primeira atividade, que indagava sobre o coeficiente angular da função afim, as respostas fornecidas pelos estudantes A, E, F, K, $\mathrm{L}, \mathrm{O}, \mathrm{P}$ e R mostram que esses conseguiram relacionar o parâmetro com a inclinação da reta, compreendendo a definição de crescente e decrescente, bem como os três registros de representação envolvidos: algébrico para a lei da função, aritmético para os valores dos coeficientes e geométrico para o gráfico da reta. A estudante $\mathrm{X}$ foi a única que utilizou em sua resposta a palavra "ângulo", manifestando o conceito de ângulo negativo. Ao total, nove alunos conseguiram percorrer todo o caminho dessa questão sem nenhuma afirmação falsa ou fora de contexto.

Figura 2 - Primeira questão da atividade sobre função afim.

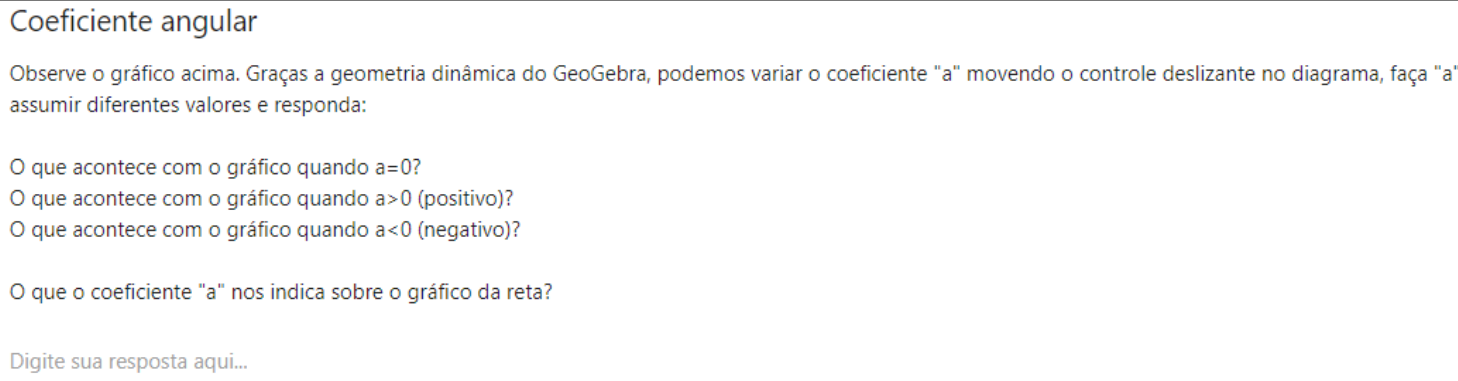

Fonte: Arquivo pessoal.

As estudantes $\mathrm{G}$ e $\mathrm{T}$ responderam de maneira coerente a questão, assim como os apresentados anteriormente, entretanto afirmaram que a reta cujo " $a$ " positivo tem ponto de mínimo e aquela cujo " $a$ " negativo tem ponto de máximo, sendo esse um equívoco entre conceitos distintos. $\mathrm{O}$ aluno $\mathrm{H}$ também compreendeu a relação com a inclinação da reta, porém afirmou também que a raiz da função de primeiro grau que tem " $a$ " positivo é sempre negativa e quando temos " $a$ " negativo a raiz é positiva. Essa conjectura poderia ser descartada com a variação do coeficiente " $b$ " e a observação de que, quando " $a$ " e " $b$ " são simultaneamente negativos, a raiz é negativa também. $\mathrm{O}$ aluno $\mathrm{S}$ cometeu o mesmo equívoco de conjectura, visto que analisou somente as raízes e nada afirmou sobre a inclinação da reta. Constatou-se que tal conjectura não foi desaprovada pelos alunos, pois eles moveram apenas o controle deslizante referente ao coeficiente " $a$ " e deixaram " $b$ " fixado. Notamos que nessa exploração conceito de 
raiz (ou zero da função) já apareceu antes mesmo de ser realizada a atividade que abordava sobre a temática.

Apesar de feita de maneira equivocada, a relação criada pelos alunos G, T, H e S mostra que, no contexto da Educação Popular, em especial no pré-vestibular, houve a manifestação de conceitos provavelmente tratados em outros momentos anteriores de suas vidas escolares. Ainda sobre questão mostrada na Figura 2, os alunos D, I, U, W e Y perceberam que o gráfico de uma reta que tem $a=0$ é sempre paralela ao eixo x, todavia responderam com pontos de retas específicas como se pertencessem a todas retas com " $a$ " positivo e negativo respectivamente, pois analisaram a posição da reta com coeficientes constantes, não observando o que acontece conforme eles variam.

O estudante $\mathrm{N}$ respondeu a primeira questão afirmando que se o coeficiente angular de uma reta é nulo, ela fica horizontal e passa no ponto de coordenadas retangulares $(1,0)$. Além da troca de $x$ por $y$ ao mencionar as coordenadas do ponto, notamos que esse estudante não conseguiu generalizar a situação, fornecendo como resposta o caso observado da reta $y=1$. Por outro lado, o estudante $\mathrm{V}$ conseguiu produzir uma generalização e respondeu que quando $a>0$ a reta cresce e quando $a<0$ a reta desce.

A segunda questão, mostrada na Figura 3, indagava sobre a relação do coeficiente linear com a posição da reta e se o gráfico sempre intercepta o eixo vertical. Os estudantes A, F, G, $\mathrm{H}, \mathrm{L}, \mathrm{O}, \mathrm{P}$ perceberam que o valor de " $b$ " interfere na altura da reta, que o ponto de coordenadas $(0, b)$ faz parte do gráfico. Observamos, em nossa leitura e interpretação da situação que isso mostra uma compressão e trânsito entre os registros gráfico, algébrico, aritmético e em língua materna das retas.

Figura 3 - Segunda questão da atividade sobre função afim.

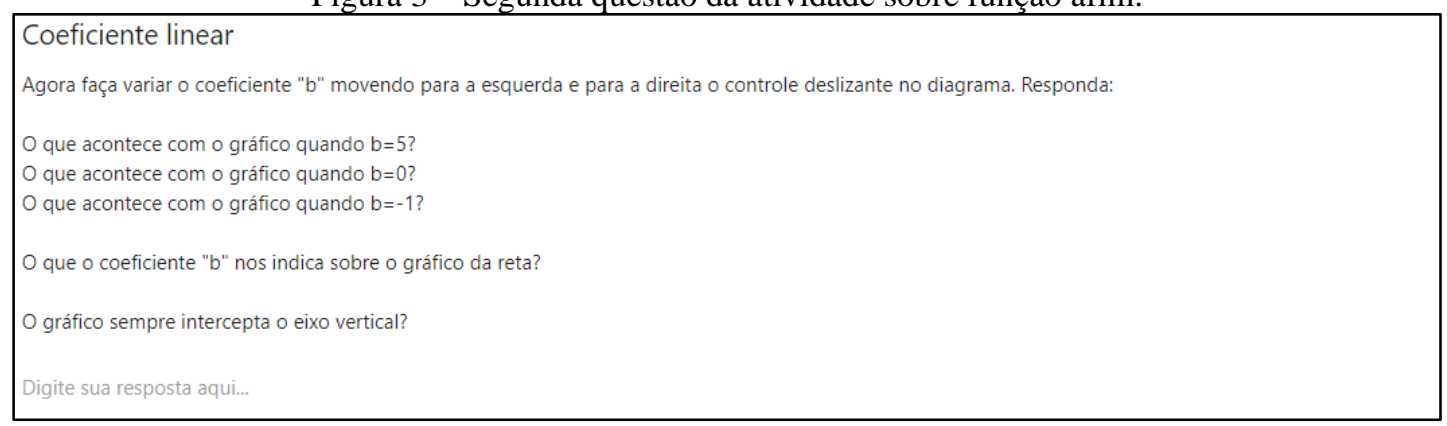

Fonte: Arquivo pessoal.

Os estudantes D, I, K, R, T, U conseguiram identificar a intersecção do eixo $y$ com a reta em questão, todavia não conseguiram generalizar o padrão observado para elaborar alguma conjectura. Observamos que essas ações mostram um trânsito entre os registros aritmético e geométrico, porém sem uma conversão para o registro algébrico. Os estudantes $\mathrm{E}$ e W afirmaram que se $b=5$ a reta é crescente e com $b=-1$ ela é decrescente, revelando uma troca conceitual no que tange a influência do coeficiente " $a$ " de uma reta pela influência do coeficiente " $b$ ". Mesmo assim, afirmaram que se $b=0$, a reta passa pela origem, o que é verdadeiro. A estudante $\mathrm{X}$ não respondeu aos questionamentos de retas específicas da questão, mas afirmou que quando $b=0$ a reta não intersecta o eixo $y$, o que é falso, pois a origem pertence ao eixo.

A terceira questão (Figura 4) solicitava para que os estudantes substituíssem os valores de " $a$ " e " $b$ " nos controles deslizantes e observasse o ponto de intersecção com o eixo $x$. Os 
participantes A, D, E, F, K, L, O, U, W e X conseguiram encontrar as raízes e a estudante G conseguiu observar as interseções, porém apresentou dificuldade na transição para o registro escrito, pois não conseguiu expressar corretamente as coordenadas dos pontos observados. Os estudantes $\mathrm{H}$ e $\mathrm{S}$ não conseguiram obter as raízes, sendo que responderam a questão com as leis das funções cujos coeficientes eram dados pelo enunciado, sem manifestar alguma compreensão sobre o conceito de raiz. Os estudantes I, P, O e T também mostraram não ter compreendido o conceito de zero de uma função, afirmando que todos os pontos de interseção do gráfico com os eixos $x$ e $y$ seriam raízes.

Figura 4 - Segunda questão da atividade sobre função afim.

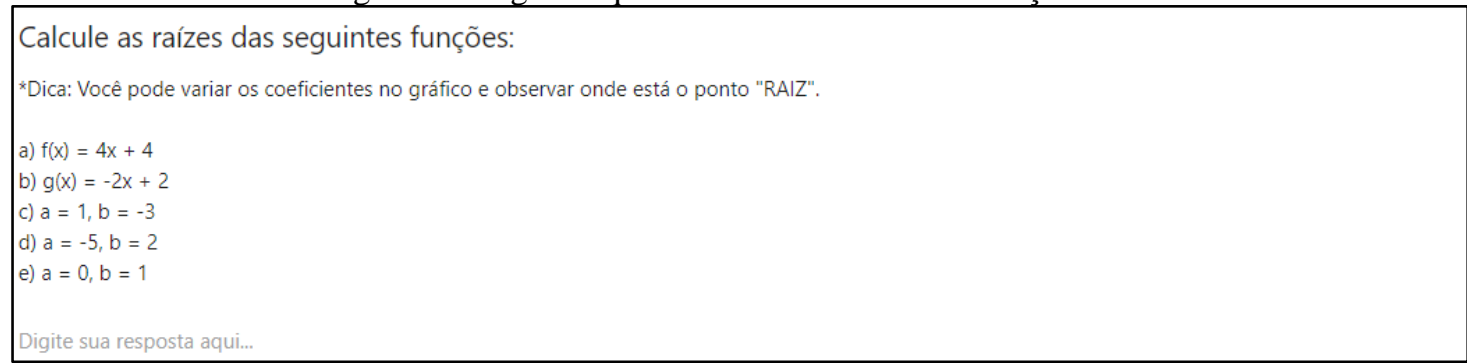

Fonte: Arquivo pessoal.

A quarta questão (Figura 5) indagava sobre a interpretação geométrica da raiz, promovendo a transformação do registro aritmético, trabalhado na questão anterior, para o registro geométrico. A quinta questão (Figura 5), de caráter dissertativo solicitava uma fórmula geral para o cálculo do zero de uma função de primeiro grau, e visava a conversão entre dois registros abordados anteriormente para o registro algébrico. A questão também indagava se o gráfico sempre interceptava o eixo horizontal.

Figura 5 - Quarta e quinta questão da atividade sobre função afim.

\begin{tabular}{|c|c|}
\hline \multicolumn{2}{|l|}{ Qual a interpretação geométrica da raiz? } \\
\hline \multicolumn{2}{|c|}{ Podemos afirmar qual(is) a(s) raiz(es) de uma função apenas observando o seu gráfico sem saber a lei da função em questão? } \\
\hline Digite sua resposta aqui... & Questão 4 \\
\hline \multicolumn{2}{|l|}{ Uma fórmula para a raiz da função de primeiro grau } \\
\hline \multicolumn{2}{|l|}{ Substituindo $f(x)=0$ (definição de zero da função) na equação geral $f(x)=a x+b$, ficamos com: } \\
\hline $\begin{array}{l}0=\mathrm{ax}+\mathrm{b} \\
\text { Isolando } \mathrm{x} \text { na equação, como podemos generalizar o valor da raiz de uma função afim? }\end{array}$ & Questão 5 \\
\hline O gráfico sempre intercepta o eixo horizontal? & \\
\hline Digite sua resposta aqui... & \\
\hline
\end{tabular}

Fonte: Arquivo pessoal.

No concernente à quarta questão, os alunos $\mathrm{A}, \mathrm{H}$ e Y afirmaram de maneira correta que a raiz é mostrada no ponto onde o gráfico intercepta o eixo das abscissas, reconhecendo até a possibilidade de existir mais de um zero da função, ao contrário das estudantes E, F, G, I, K, L, P e T que mencionaram "raiz" no singular em sua resposta sem mais evidências de reflexão sobre o assunto. A participante $\mathrm{X}$ afirmou que quando não há raiz, não existe ângulo entre a reta e os eixos coordenados, afirmação que, apesar de correta, foi mencionada fora de contexto. Para efeitos de registro e sem que pudessem gerar mais reflexões os alunos D e W responderam apenas "sim". 
Sobre as respostas fornecidas para a quinta questão, os estudantes G, P, T e X construíram a relação $x=-b / a$, isolando o " $x$ " na equação $y=a x+b$, e justificaram corretamente que a reta nem sempre intercepta o eixo das abscissas. A estudante $\mathrm{Y}$ forneceu como resposta a expressão " $x=a+b$ ", a qual não fornece de forma correta qual seja a raiz da função e também não afirmou se a reta sempre interceptará ou não o eixo $x$. Os estudantes $\mathrm{F}$, I e L descreveram uma relação para o zero de uma função afim, mas responderam que o gráfico sempre intercepta o eixo $x$, desconsiderando o caso em que $a=0$. Entendemos que de forma geral o desafio de realizar um tratamento algébrico proposto no problema foi bem compreendido pelos participantes, os quais conseguiram construir e expressar uma relação matemática que fornece a raiz da função, entretanto notamos que nesse processo não houve em alguns casos uma interpretação correta do registro aritmético aos que não perceberam a impossibilidade de divisão por zero.

A atividade sobre função quadrática contemplou questionamentos sobre os coeficientes " $a$ ", " $b$ " e " $c$ " em $f(x)=a x^{2}+b x+c$, interpretação do quantitativo de raízes reais, ponto de vértice, forma fatorada e construção da lei da função. Sobre o papel do coeficiente " $a$ " os estudantes B, G, H e M perceberam a influência desse na concavidade da parábola, posicionada virada para cima ou para baixo, e tentaram mobilizar registros de representação aritmético e geométrico na construção de alguma resposta. Os estudantes C, I, J, Q, R e U também perceberam o que acontece quando " $a$ " varia, mas não apontaram nenhuma justificativa, mesmo sendo requisitado. A estudante $X$ também não forneceu justificativa, porém ao invés de responder com a concavidade, afirmou que a função tem um ponto máximo quando $a<0$ e um ponto mínimo quando $a>0$. Observamos nesse momento da atividade que o conceito de vértice apareceu antes de ser abordado explicitamente na atividade, mostrando o resgate e mobilização dos conhecimentos anteriores dos estudantes.

A questão seguinte, sobre a influência do coeficiente " $b$ ", era uma das características menos triviais de ser percebida, sendo que somente os estudantes G e R conseguiram observar que ele direciona se a parábola intercepta o eixo $y$ de maneira crescente ou decrescente. Todavia não perceberam o caso em que " $b$ " é igual a zero, e o vértice está sobre o eixo, nessa parte, o aluno $\mathrm{R}$ argumentou que a função com $b=0$ não tem raiz, o que é falso. As estudantes $\mathrm{B}, \mathrm{C}$, $\mathrm{M}$ e $\mathrm{Q}$ afirmaram que o coeficiente faz com que a função se desloque para a esquerda e para a direita, o que está correto para " $a$ " positivo. O teste no caso em que " $a$ " é negativo não foi feito, o que impediu a construção de uma argumentação global sobre o padrão observado. $\mathrm{O}$ participante $\mathrm{H}$ fez a mesma afirmação, porém utilizando o conceito de vértice, abordado apenas nas próximas questões da atividade, e a estudante $X$ forneceu também a mesma resposta, com o raciocínio sendo feito a partir da posição do gráfico de acordo com os quadrantes. O estudante J não observou um padrão, mas afirmou que o valor de " $b$ " interfere na quantidade de raízes de uma função de segundo grau, o que é falso. A participante I não conseguiu transitar entre o registro gráfico e o registro verbal para explicar o padrão que observou.

Quanto ao coeficiente "c" notou-se que os estudantes B, C, H e Q conseguiram realizar a transição entre registros, percebendo a relação entre o coeficiente e a intersecção do gráfico da função com o eixo $y$, porém não apresentaram argumento que justificasse essa relação. A estudante $G$ percebeu e justificou a influência do coeficiente "c" na posição da parábola, realizando a conversão entre os registros algébrico, geométrico e verbal. Entretanto não os relacionou com a interpretação aritmética pontual ao afirmar apenas que a parábola fica posicionada abaixo do eixo quando assume um valor negativo. Os estudantes I, J, R e X não conseguiram observar o padrão e fizeram afirmativas que dizem respeito à influência de outros coeficientes. Além de incorrer o mesmo erro, a participante $M$ não conseguiu expressar o 
registro algébrico, apenas comentou o padrão observado sem responder onde a parábola intercepta o eixo vertical para os casos do enunciado.

A questão que tratava sobre as raízes da função quadrática os participantes B, C, G, I e Q conseguiram observar e argumentar sobre o número de raízes para os três casos requisitados (positivo, negativo e igual a zero) e também apresentaram justificativas afirmando que se deve ao "número de respostas" da fórmula resolvente. Outros estudantes, $\mathrm{R} \mathrm{e} \mathrm{H}$, perceberam o mesmo padrão, mas não apresentaram nenhuma explicação.O participante $\mathrm{J}$ conjecturou que, se o delta $\left(b^{2}\right.$ - 4.a.c em $\left.f(x)=a x^{2}+b x+c\right)$ fosse positivo, a função tem raízes positivas e, se o delta é negativo, a função tem raízes negativas, o que é falso mediante observação. Além disso, o mesmo afirmou que o valor do delta varia conforme o coeficiente " $b$ ", o que é verdade, porém insuficiente.

Na sequência foi questionado sobre o vértice da função, o qual requisitava do estudante observações sobre o gráfico e a localização do ponto máximo ou mínimo marcado no diagrama interativo. Mesmo sem responder se o ponto era de máximo ou mínimo, os estudantes B, C, G, $\mathrm{H}, \mathrm{J}$ e Q identificaram as coordenadas do vértice e as escreveram de maneira correta. Apenas a estudante I apresentou corretamente em suas respostas se o ponto é máximo ou mínimo, o que foi oportunizado construir a partir do gráfico e pode levar a estudante a conjecturar de que, quando $a>0$ o vértice seria ponto mínimo e, no caso $a<0$, o vértice é o ponto máximo da função. O estudante R, apesar de ter utilizado os conceitos de ponto máximo e mínimo, não mencionou corretamente as coordenadas dos vértices das funções em questão e afirmou que a relação $f(x)$ $=x^{2}$ tem a forma de uma reta. Entendemos que tal erro tenha ocorrido por uma falha na identificação do valor do coeficiente " $a$ ", não ocorrendo assim uma transição correta entre o registro algébrico e o aritmético.

Quanto aos argumentos e respostas apresentadas na penúltima questão da atividade que abordava a forma fatorada da função quadrática, percebeu-se que os estudantes $\mathrm{C}$ e Q apresentaram as leis correspondentes aos valores requisitados como raízes e conseguiram identificar que o coeficiente " $b$ " é igual a zero quando eles são opostos, porém não fizeram conjecturas válidas para a lei de uma função que tem zero como uma das raízes. Os estudantes B, G e H responderam corretamente as leis da questão, mas não apresentaram conjecturas válidas nas perguntas dissertativas. Por fim, os estudantes I e R apesar de fornecerem respostas corretas, não manifestaram elementos de seu processo argumentativo.

A última questão de cada atividade consistiu em um problema apresentado em provas de exames avaliativos nacionais (ENEM, vestibular), os quais mobilizaram diferentes formas de representação e transição entre os registros de representação. Entendemos que a participação dos estudantes nessas atividades de certa forma consolidou o percurso realizado de modo prévio, destacando o potencial de um fazer pedagógico que valoriza a intradisciplinaridade como modo de produção de significados. Ao longo da experiência de pesquisa aqui relatada foi possível verificar a construção e transição de diferentes registros de representação, permeados por ações cognitivas dos participantes frente aos desafios impostos pelas questões abordadas. Entendemos também nesse momento que é necessário um exercício de autocrítica, o que permite concluir que o conjunto de atividades realizadas não constitui um conjunto fechado e acabado, mas sim um conjunto de atividades que pode ser melhorado e faça parte de outras práticas de ensino, com participantes distintos e que provavelmente produzirão reflexões e transições entre os registros de representação distintos dos mostrados no presente texto. 


\section{Considerações Finais}

O Dandara dos Palmares é um pré-vestibular popular e, como tal, enfrenta dificuldades que são particulares desse sistema de ensino, como a evasão e a variação semanal de estudantes presentes nas aulas. Entendemos que pelo fato dos discentes que frequentam tais espaços educacionais por vezes estarem em situações de vulnerabilidade social esse seja um motivo pelo qual eles estejam mais expostos à evasão por problemas relacionados à família, dinheiro, dificuldade de transporte e emprego. Além disso, os estudantes trazem diferentes experiências escolares e de vida para o trabalho em sala de aula, o que pode causar certa confusão entre os conceitos compreendidos erroneamente durante a idade escolar. Nesse contexto, foi possível, por meio da nossa análise das respostas fornecidas pelos estudantes, observar que apenas parte deles conseguiu transitar entre os diferentes registros de representação semiótica do objeto matemático em questão.

Entendemos a partir da experiência de ensino realizada que a transformação entre os registros e a sua compreensão individual foi de certa forma influenciada pelo software usado, no qual ao fornecer objetos virtuais interativos, em que o participante pudesse alterar os coeficientes e acompanhar em tempo real a sua consequência no gráfico da função, permitiu assim uma visualização e construção de relações entre os registros algébrico, aritmético e geométrico. Esse trabalho mostra ser possível uma aproximação entre os eixos algébrico, aritmético e geométrico, observados em diferentes contextos, destacando uma convergência sob a perspectiva da intradisciplinaridade matemática. Essa potencialidade já foi observada e manifestada em outras pesquisas, tais como Perius (2012), e consideramos que essa aproximação seja o ponto que buscamos para tentar responder a nossa questão de pesquisa. $\mathrm{O}$ ponto que destacamos é que a disponibilidade e uso de materiais didáticos no formato digital que oportunizem construir e mobilizar diferentes registros de representação fornece elementos que são essenciais aos sujeitos na direção da aprendizagem matemática.

Por meio dos trabalhos correlatos consultados, os resultados obtidos por nós dialogam com as potencialidades mencionadas no trabalho de Madruga (2017), em que o autor reconhece que o uso de um software educativo em sala de aula pode causar uma interação futura por parte do estudante moderno, já que ele está constantemente conectado à internet pela tela do celular. Entendemos que o conhecimento técnico relativo à operação do aplicativo seja importante para o desenvolvimento cognitivo do estudante e apresentam-se potencialidades para o estudo de matemática e de seus conteúdos específicos.

Por fim, a partir da experiência de pesquisa realizada em um espaço de Educação Popular percebemos sua importância, relação e necessidade de diálogo com a formação de professores, seja ela inicial ou continuada. Freire (2013) afirmou que além de ser necessária a formação dos professores reflexivos sobre essa temática, que nesse espaço deve-se potencializar a dualidade sobre o que seja ser, concomitantemente, professor e aluno. Finalmente, destacamos a título de informação que dos 25 participantes que tiveram os dados analisados na nossa pesquisa, 14 foram aprovados em exames e ingressarão no Ensino Superior a partir do ano de 2020.

\section{Agradecimentos}

Ao Instituto Federal de Educação, Ciência e Tecnologia do Rio Grande do Sul (IFRS) pelo acolhimento e parceria na execução da pesquisa realizada. 
Referências

BRANDÃO, Carlos Rodrigues. O que é Educação Popular. São Paulo: Brasiliense, 2006.

BRASIL. Orientações Curriculares para o Ensino Médio. Ciências da Natureza, matemática e suas tecnologias. Brasília: Ministério da Educação, Secretaria de Educação Básica, 2006.

DOTTA, Silvia. Uso de uma Mídia Social como Ambiente Virtual de Aprendizagem. In:XXII Simpósio Brasileiro de Informática na Educação -XVII WIE. Aracaju, AL, Brasil, 2011.

DUVAL, Raymond. Semiósis e pensamento humano: registros semióticos e aprendizagens intelectuais. Tradução: Lênio Fernandes Levy e Marisa Rosâni Abreu da Silveira. São Paulo: Editora livraria da física, 2009.

FANTIN, Mônica; GIRARDELLO, Gilka. Diante do abismo digital: mídia-educação e mediações culturais. Perspectiva, Florianópolis, v. 27, n. 1, 69-96, jan./jul., 2009.

FANTIN, Mônica; RIVOLTELLA, Pier Cesare. Cultura digital e formação de professores: usos da mídia, práticas culturais e desafios educativos. In: FANTIN, Monica; RIVOLTELLA, Pier Cesare. (org.). Cultura digital e escola: pesquisa e formação de professores. Campinas (SP): Papirus, 2003.

FARIA, Rejane Waiandt Schuwartz de Carvalho; MALTEMPI, Marcus Vinicius. Intradisciplinaridade Matemática com GeoGebra na Matemática Escolar. Bolema, Rio Claro (SP), v.33, n.63, p. 348-367, abr. 2019.

FAVARÃO, Maria José. Educação, participação política e direitos humanos. Gestão escolar e educação em direitos humanos. São Paulo: Editora e livraria Paulo Freire, p. 189-214, 2011.

FIORENTINI, Dario; LORENZATO, Sergio. Investigação em educação matemática: Percursos teóricos e metodologias. 3.ed. Campinas: Autores Associados, 2007. Coleção formação de professores.

FISS, Dóris Maria Luzzardi et al. A EJA em três temas: evasão, tempos da vida e prática pedagógica. In: GODINHO, Ana Claudia Ferreira et al. (org.). Entre imagens e palavras: práticas e pesquisas na EJA, p. 151-163. Porto Alegre: Editora Panorama Crítico, 2012.

FREIRE, Paulo. Pedagogia da autonomia: saberes necessários para a prática educativa. 44. ed. Rio de Janeiro: Paz \& Terra, 2013.

FREIRE, Paulo. Pedagogia do oprimido. 9. ed. Rio de Janeiro: Paz \& Terra, 1981.

HENRIQUES, Afonso; ALMOULOUD, Saddo Ag. Teoria dos registros de representação semiótica em pesquisas na Educação Matemática: uma análise de superfícies e funções de duas variáveis com intervenção do software Maple. Ciência Educação, Bauru, v. 22, n. 2, p. 465-487, 2016. 
LOUZADA, Alana Gomes Tomaz. Geometria dinâmica 3D: uma experiência com Geogebrabook no ensino da geometria espacial. Trabalho de conclusão de curso, Universidade Federal do Rio Grande do Sul, Porto Alegre, RS, Brasil, 2018.

MADRUGA, Zulma Elizabete de Freitas. Recursos tecnológicos como apoio no ensino presencial e a distância da disciplina de matemática.In: II Seminário Diálogos em Educação a Distância. Pelotas, RS, Brasil, 2017.

MASSENSINI, Rogério Luís. Inclusão digital: sob a ótica da cidadania plena.

DataGramaZero: Revista da ciência e informação - v.12 n.2 abr/11, 2011.

MORETTI, Méricles Tadeu. Registros de representação semiótica e funcionamento cognitivo do pensamento. Revemat: Rev. Eletr. De Edu. Mat. Florianópolis, v. 07, n. 2, p. 266 - 297, 2012.

NOTARE, Márcia Rodrigues; FIOREZE, Leandra Anversa; HALBERSTADT, Fabrício F. O Software Grafeq e os Registros de Representação Semiótica: Uma Análise de Trabalhos com Ilusão de Ótica. In: XIV Conferência Interamericana de Educação Matemática: XIV CIAEM, Tuxtla, 2015.

PEREIRA, Dulcinéia de Fátima Ferreira; PEREIRA, Eduardo Tadeu. Revisitando a história da educação popular no Brasil: em busca um outro mundo possível. Revista HISTEDBR online, Campinas, n.40, p.72-89, dez. 2010.

PERIUS, Ana Amélia Butzen. A tecnologia aliada ao ensino de matemática. Trabalho de Conclusão de Curso de Especialização, Universidade Federal do Rio Grande do Sul, Cerro Largo, RS, Brasil, 2012.

PETRIS, Vânia Fuchter. O desafio da educação na cultura digital. Trabalho de Conclusão de Curso, Universidade Federal de Santa Catarina, Taió, SC, Brasil, 2016.

PINI, Francisca Rodrigues de Oliveira, ADRIANO, Ana Lívi. Educação em direitos humanos: abordagens teórico-metodológicas e ético-políticas. In: PINI, Francisca Rodrigues de Oliveira; MORAES. Célio Vanderlei. Educação, participação política e direitos humanos. São Paulo: Editora e livraria Paulo Freire, p. 15-29, 2011.

PINI, Francisca Rodrigues de Oliveira. Educação popular e seus diferentes espaços: Educação social de rua, prisional e do campo. IV Congresso Internacional de Pedagogia, São Paulo, SP, Brasil, 2012.

REZAT, Sebastian. Learning mathematics with text books. PME 32 and PME-NA XXX. Universität Giessen, Deutschland, p. 177-184, 2008.

RIBEIRO, Elvia Nunes; MENDONÇA, Gilda Aquino de Araújo; MENDONÇA, Alzino Furtado de. A importância dos ambientes virtuais de aprendizagem na busca de novos domínios da EAD. Centro Federal de Educação Tecnológica de Goiás, Goiânia, GO, Brasil, 2007. 
SANTAELLA, Lucia. Culturas e artes do pós-humano: da cultura das mídias à cibercultura. São Paulo: Paulus, 2003.

SCHWARTZ, Gilson. Exclusão digital entra na agenda econômica mundial. Folha de São Paulo, São Paulo, 18 de janeiro de 2000.

SILVA, Rodrigo Sychocki da; PINTO, Shéridan dos Reis. Funções quadráticas e tecnologias móveis: ações cooperativas em um experimento no Ensino Médio. Góndola, Enseñanza y Aprendizaje de las Ciencias, v.14, n.1, p. 108-125, 2019.

SILVA, Rodrigo Sychocki da. O uso de problemas no ensino e aprendizagem de funções exponenciais e logarítmicas na Escola Básica. Dissertação de Mestrado, Universidade Federal do Rio Grande do Sul, Porto Alegre, 2012.

Recebido em março de 2020.

Aprovado em maio de 2020. 